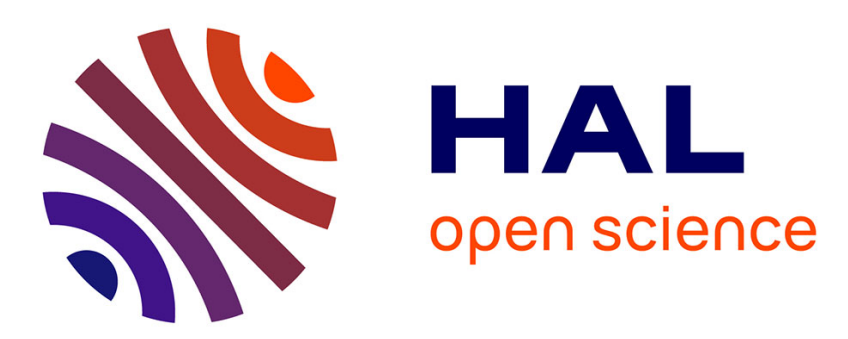

\title{
ANISOTROPY AND MAGNETOSTRICTION OF 4d AND 5d TRANSITION-METAL IONS IN GARNETS AND SPINEL FERRITES
}

P. Hansen, R. Krishnan

\section{- To cite this version:}

P. Hansen, R. Krishnan. ANISOTROPY AND MAGNETOSTRICTION OF 4d AND 5d TRANSITION-METAL IONS IN GARNETS AND SPINEL FERRITES. Journal de Physique Colloques, 1977, 38 (C1), pp.C1-147-C1-155. 10.1051/jphyscol:1977130 . jpa-00216990

\section{HAL Id: jpa-00216990 https://hal.science/jpa-00216990}

Submitted on 1 Jan 1977

HAL is a multi-disciplinary open access archive for the deposit and dissemination of scientific research documents, whether they are published or not. The documents may come from teaching and research institutions in France or abroad, or from public or private research centers.
L'archive ouverte pluridisciplinaire HAL, est destinée au dépôt et à la diffusion de documents scientifiques de niveau recherche, publiés ou non, émanant des établissements d'enseignement et de recherche français ou étrangers, des laboratoires publics ou privés. 


\title{
ANISOTROPY AND MAGNETOSTRICTION OF 4d AND 5d TRANSITION-METAL IONS IN GARNETS AND SPINEL FERRITES
}

\author{
P. HANSEN \\ Philips GmbH Forschungslaboratorium Hamburg, 2 Hamburg 54, BRD \\ R. KRISHNAN \\ Laboratoire de Magnétisme, C. N. R. S. 92190 Bellevue, France
}

\begin{abstract}
Résumé. - Grâce à leur couplage spin-orbite très fort, les ions des séries $4 \mathrm{~d}$ et $5 \mathrm{~d}$ apportent une contribution importante aux propriétés anisotropes des ferrites et grenats. En particulier les ions $\mathrm{d}^{5}$ en état de spin bas, tels que $\mathrm{Ru}^{3+}, \mathrm{Os}^{3+}, \mathrm{Rh}^{4+}$ et $\mathrm{Ir}^{4+}$, présentent un intérêt particulier car leurs niveaux d'énergie les plus bas, qui déterminent leurs propriétés magnétiques, ont une structure simple.

Les contributions à l'anisotropie et à la magnétostriction peuvent être explicitement calculées dans le cadre de la théorie à un ion et dans la gamme de températures $0 \leqslant T \leqslant T_{\mathrm{c}}$, ce qui n'est plus possible pour d'autres ions anisotropes.

La comparaison entre théorie et résultats expérimentaux fournit un excellent accord dans les cas choisis, ce qui étaye l'hypothèse simple du modèle à un ion dans le cas d'un système magnétique ordonné.

Abstract. - Some 4d and 5d transition-metal ions are expected to contribute significantly to the anisotropic properties of ferrites and garnets owing to their strong spin-orbit coupling. In particular the low-spin $\mathrm{d}^{5}$ ions such as $\mathrm{Ru}^{3+}, \mathrm{Os}^{3+}, \mathrm{Rh}^{4+}$ and $\mathrm{Ir}^{4+}$ are of special interest since they exhibit a very simple level structure of their lowest energy levels which determine the magnetic behaviour. For these ions the contributions to anisotropy and magnetostriction can be calculated explicitely within the single-ion theory for the complete temperature range $\left(0 \leqslant T \leqslant T_{\mathrm{c}}\right)$ in contrast to other strongly anisotropic ions. The comparison of the theory with experimental results yields excellent agreement for selected cases supporting the simple conception of the single-ion model in magnetically ordered systems in correspondence to paramagnetic materials.
\end{abstract}

1. Introduction. - The presence of magnetic anisotropy and magnetostriction in each magnetic material assigns to these properties a central role in the basic research and the device applications of magnetic materials. The magnetic oxides of garnet and spinel structure are mostly pure insulators which makes them very attractive for studying the anisotropic phenomena, since in contrast to the metals simpler models can be used to explain the basic effects. In ferrites and garnets attention has been drawn so far to the anisotropic behaviour of the $3 \mathrm{~d}$ transition-metal ions and rare earth ions except for some studies in the recent past concerning some ions of the second and third transition series. This situation certainly is due to the fact that ferrimagnetism of magnetic oxides essentially is based on $3 \mathrm{~d}$ transition-metal ions and rare earth ions. However, in the discussion of anisotropic porperties the ions of the second and third transition series are of special interest. In particular the ruthenium and iridium ions were characterized by a strong anisotropic behaviour as it was expected from their energy level structure [1]. For a certain valence state $\left(\operatorname{Ru}^{3+}\left(4 d^{5}\right), \operatorname{Ir}^{4+}\left(5 d^{5}\right)\right)$ and at a certain crystallographic site they exhibit the most simple level structure of all anisotropic ions and thus the theory of anisotropy and magnetostriction of these ions can be simply derived in an explicite form for the complete temperature range which is not yet possible for any other anisotropic ion. In this sense these ions represent an exceptional case and can be regarded as an important proof for the validity of the single-ion theory in the field of magnetic oxides.

Phenomenologically the anisotropy and magnetostriction can be expressed uniformly for all magnetic materials of corresponding crystal symmetry independently of the microscopic origin of these effects. Garnets and spinel ferrites are cubic and therefore the anisotropic part of the free energy can be described for both by the same expression. The free energy depending on the direction $\alpha$ of the magnetization and the strain tensor $\overleftrightarrow{\boldsymbol{\varepsilon}}$ generally is of the form

$$
F(\boldsymbol{\alpha}, \overleftrightarrow{\boldsymbol{\varepsilon}})=F_{0}+F_{\mathrm{e}}(\stackrel{\leftrightarrow}{\boldsymbol{\varepsilon}})+F_{K}(\boldsymbol{\alpha})+F_{\mathrm{me}}(\boldsymbol{\alpha}, \overleftrightarrow{\boldsymbol{\varepsilon}})
$$

where $F_{0}$ is a constant with respect to $\alpha$ and $\overleftrightarrow{\varepsilon}, F_{\mathrm{c}}(\overleftrightarrow{\varepsilon})$ represents the pure elastic energy, $F_{K}(\alpha)$ is the magnetocrystalline anisotropy and the last term denotes the magnetoelastic energy. For cubic symmetry $F_{K}(\alpha)$ is given by :

$$
\begin{aligned}
F_{K}(\alpha) & =K_{1} s+K_{2} p+K_{3} s^{2}+K_{4} s p+\cdots \\
s & =\alpha_{1}^{2} \alpha_{2}^{2}+\alpha_{2}^{2} \alpha_{3}^{2}+\alpha_{1}^{2} \alpha_{3}^{2}, \quad p=\alpha_{1}^{2} \alpha_{2}^{2} \alpha_{3}^{2} .
\end{aligned}
$$


$K_{i}$ are the anisotropy constants. The magnetoelastic energy can be expressed in terms of the components of $\alpha$ and $\overleftrightarrow{\varepsilon}$ by

$$
\begin{aligned}
& F_{\mathrm{mc}}(\boldsymbol{\alpha}, \overleftrightarrow{\varepsilon})=b_{1}\left(\varepsilon_{11} \alpha_{1}^{2}+\varepsilon_{22} \alpha_{2}^{2}+\varepsilon_{33} \alpha_{3}^{2}\right)+ \\
& \quad+b_{2}\left(\varepsilon_{12} \alpha_{1} \alpha_{2}+\varepsilon_{23} \alpha_{2} \alpha_{3}+\varepsilon_{13} \alpha_{1} \alpha_{3}\right)+\cdots
\end{aligned}
$$

where the $b_{i}$ are the magnetoelastic constants. They are related to the magnetostriction constants $\lambda_{100}$ and $\lambda_{111}$ via the relations

$$
\lambda_{100}=-\frac{2}{3} \frac{b_{1}}{C_{11}-C_{12}}, \quad \lambda_{111}=-\frac{1}{3} \frac{b_{2}}{C_{44}} .
$$

The $C_{i k}$ are the elastic constants. For most spinel ferrites and garnets the first two constants of eqs. (2) and (3) are sufficient to describe the observed effects.

The influence of anisotropic transition-metal ions on the $K_{i}$ and $\lambda_{h k l}$ is displayed in figure $1 a, b$ and $2 a, b$ at room temperature. Very strong changes of the

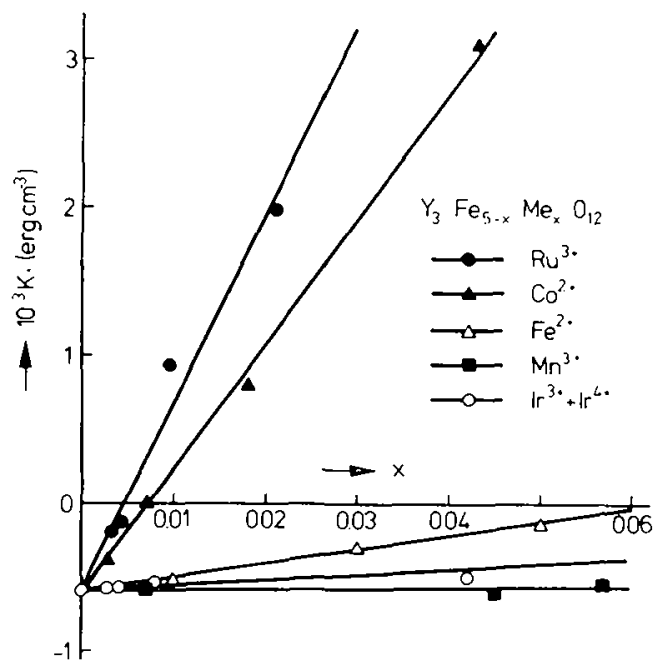

(a)

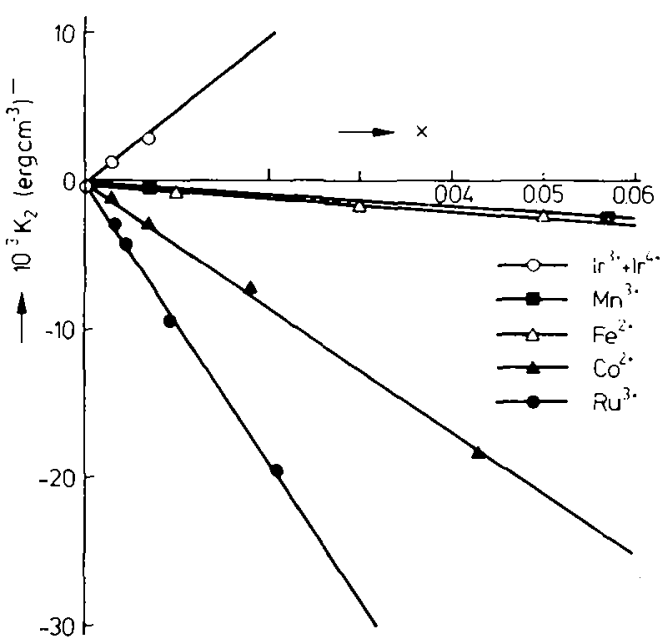

(b)

FIG. 1. - Room temperature anisotropy constants versus concentration $a$ ) $\mathrm{K}_{1}$ and $b$ ) $\mathrm{K}_{2}$ of yttrium iron garnet substituted with the $3 \mathrm{~d}$ ions $\mathrm{Mn}^{3+}[2], \mathrm{Fe}^{2+}[3,4], \mathrm{Co}^{2+}[5]$ and the $4 \mathrm{~d} / 5 \mathrm{~d}$ ions $\mathrm{Ru}^{3+}[6-9], \mathrm{Ir}^{3+}+\operatorname{Ir}^{4+}[7,12]$.

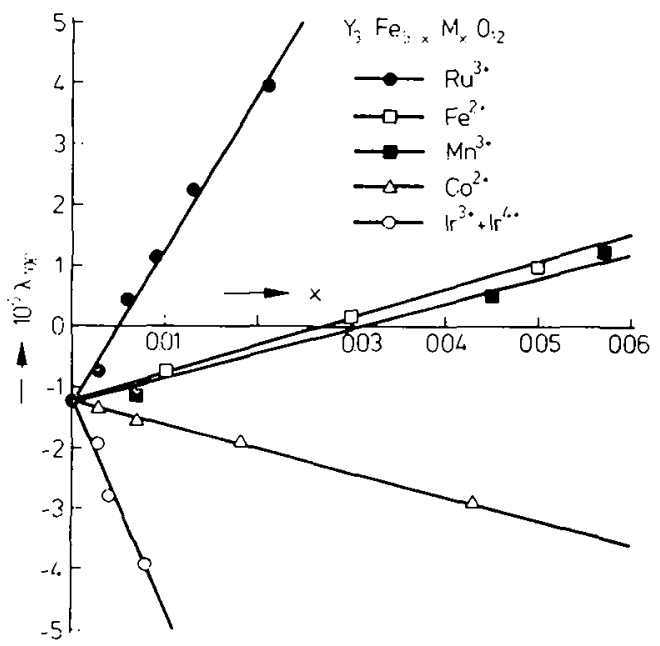

(a)

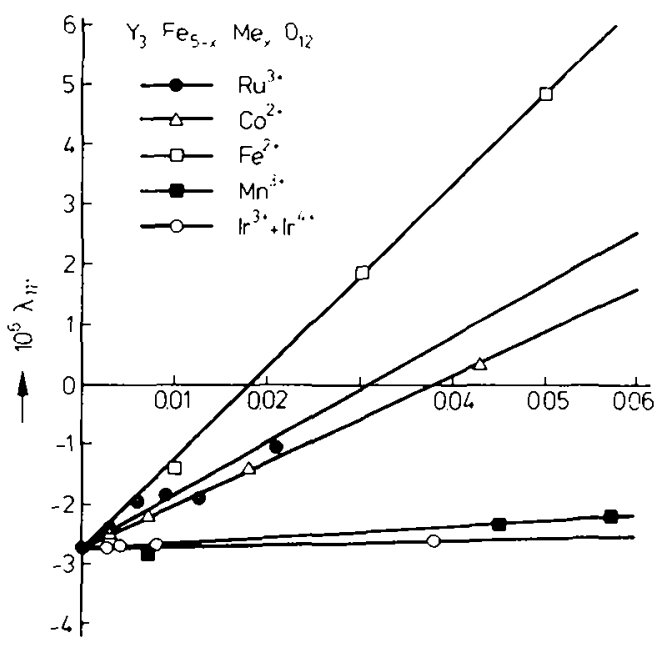

(b)

FIG. 2. - Room temperature magnetostriction constants versus concentration a) $\lambda_{1100}$ and b) $\lambda_{111}$ of yttrium iron garnet substituted with the $3 \mathrm{~d}$ ions $\mathrm{Mn}^{3+}[2], \mathrm{Fe}^{2+}[3,4], \mathrm{Co}^{2++}[5]$ and the $4 \mathrm{~d} / 5 \mathrm{~d}$ ions $\mathrm{Ru}^{3+}[10,11,23] \mathrm{Ir}^{3+}+\operatorname{Ir}^{4+}[12,13]$

anisotropy and the magnetostriction constants already occur for both the $3 \mathrm{~d}$ ions $\mathrm{Mn}^{3+}\left(3 \mathrm{~d}^{4+}\right)$ [2], $\mathrm{Fe}^{2+}\left(3 \mathrm{~d}^{6}\right)[3,4], \mathrm{Co}^{2+}\left(3 \mathrm{~d}^{7}\right)[5]$ and the $4 \mathrm{~d} / 5 \mathrm{~d}$ ions $\mathrm{Ru}^{3+}\left(4 \mathrm{~d}^{5}\right)$ [6-11] and $\mathrm{Ir}^{4+}\left(5 \mathrm{~d}^{5}\right)[7,12-13]$ at very small concentrations. For other ions like $\mathrm{Fe}^{3+}[14]$, $\mathrm{Cr}^{3+}[15]$ or $\mathrm{Cu}^{2+}[1.6]$ no variation would be seen in this representation (see table II). Their contribution is very small owing to their orbitally nondegenerate cubic ground state which in first order gives no contribution to anisotropy and magnetostriction. The ions presented in figures 1 and 2, however, are characterized by an orbitally degenerate cubic ground state and in addition by a strong spin-orbit coupling which fixes the spin system to certain crystallographic directions. Since the spin-orbit coupling of the $4 \mathrm{~d}$ and $5 \mathrm{~d}$ ions is much larger as compared to that of the $3 \mathrm{~d}$ ions they are expected to be candidates for strong anisotropic effects which is supported by the changes of $K_{i}$ and 
$\lambda_{h k l}$ induced by the ruthenium and iridium ions. Most attention was drawn to these ions because on one hand their level structure predicts the most prominent effects and on the other hand the chemical properties of the corresponding oxides are appropriate for their incorporation in the crystal lattice of garnets and spinel ferrites.

The ions presented in figures 1 and 2 occupy preferentially octahedral sites and this is important for the sign and magnitude of their anisotropic contribution. The local symmetry is one of the most important factors together with the spin-orbit coupling which are responsible for the observed effects. Spinel ferrites are of the composition (A) $\left[\mathrm{B}_{2}\right] \mathrm{O}_{4}$ and the magnetic ions occupy the two sites. The $\mathrm{A}$ and $\mathrm{B}$ sites are tetrahedrally and octahedrally surrounded by oxygen ions, respectively. Garnets are of the composition $\left\{\mathrm{C}_{3}\right\}\left[\mathrm{B}_{2}\right]\left(\mathrm{A}_{3}\right) \mathrm{O}_{12}$ where in addition to the above two sites the $\mathrm{C}$-site with a eight-fold oxygen coordination is present. In iron garnets these sites are occupied by large ions as the rare earth ions and their occupation by transition-metal ions is unlikely. Therefore we will restrict our considerations to the octahedral and tetrahedral sites in both types of ferrimagnetic compounds and thus for both general considerations are valid.

The aim of this paper is the presentation of a simple explanation of the observed effects of these $4 \mathrm{~d}$ and $5 \mathrm{~d}$ transition-metal ions in terms of the single-ion theory which already has been successfully applied to $3 \mathrm{~d}$ ions and to discuss their effects with respect to the site occupation and valence state.

2. Theory. - 2.1 Free energy. - From the linear concentration dependence of the anisotropy and magnetostriction constants it can be concluded that the probability to form pairs or clusters of the substituted ions is quite low for these small concentrations and thus only the effect of single ions in the garnet or spinel host have to be considered. If one percent of the octahedral iron ions is replaced by anisotropic ions which will be assumed to be statistically incorporated in the lattice, then, roughly in every fifth unit cell one of these ions is present. Therefore, the interaction between these ions will be very small and can be neglected in good approximation. These conditions, however, are just those which have to be met if the framework of the single-ion theory can be used to explain these anisotropic effects. This theory has been successfully applied to explain the anisotropic behaviour of $3 \mathrm{~d}$ transition-metal ions even for high concentrations [7-9].

The contribution of the substituted anisotropic ions to the free energy $\Delta F(\alpha, \stackrel{\leftrightarrow}{\varepsilon})$ then can be expressed in terms of the single-ion contribution $f^{(i)}(\alpha, \overleftrightarrow{\varepsilon})$ times the number of ions $N$ per $\mathrm{cm}^{3}$ :

$$
\Delta F(\alpha, \overleftrightarrow{\varepsilon})=\frac{N}{n} \sum_{i=1}^{n} f^{(i)}(\alpha, \overleftrightarrow{\varepsilon})
$$

The summation extends over the magnetically inequivalent sites (dodecahedral : $n=6$, octahedral : $n=4$, tetrahedral $: n=3) . f^{i}(\alpha, \overleftrightarrow{\varepsilon})$ is given by the expression :

$$
f^{(i)}(\alpha, \overleftrightarrow{\varepsilon})=-k T \ln \left[\sum_{j} \exp \left(-\frac{E_{i j}(\alpha, \overleftrightarrow{\varepsilon})}{k T}\right)\right]
$$

where $E_{i j}(\alpha, \overleftrightarrow{\varepsilon})$ are the energy levels of the ion on site $i$ Thus, the main task has to be focussed on the problem of calculating the energy levels of such ions as a function of the direction of magnetization and the strain. An explicite solution of this problem can be expected only for very simple configurations where the relative magnitude of the present interactions provides marked simplifications in the mathematics.

The interactions which determine the ground state of these ions in a given host and the coupling between the spin system and the lattice may be quite different in magnitude for different anisotropic ions. But all anisotropic ions roughly can be divided into three groups arranged with respect to the relative magnitude of the interactions [21]. As shown in table I the $3 \mathrm{~d}$ ions form a group, then the $4 \mathrm{~d}$ and $5 \mathrm{~d}$ ions and the rare earth ions where the latter may only serve for comparison. The cubic ground state is determined by the interaction of the electrons of the unfilled d-shell $E_{\mathrm{el}}^{\mathrm{d}}$ and the cubic crystalline field energy $E_{\mathrm{c}}^{\mathrm{cub}}$. The main difference in the cubic ground state between the $3 \mathrm{~d}$ and the $4 \mathrm{~d} / 5 \mathrm{~d}$ ions is their spin state. Since $E_{\mathrm{el}}^{\mathrm{d}}>E_{\mathrm{c}}^{\mathrm{cub}}$ for the $3 \mathrm{~d}$ ions, they exhibit a high-spin state $\left(\mathrm{Fe}^{3+}\left(3 \mathrm{~d}^{5}\right): S=5 / 2\right)$ while for $4 \mathrm{~d} / 5 \mathrm{~d}$ ions $E_{\mathrm{d}}^{\mathrm{cub}}>E_{\mathrm{el}}^{\mathrm{c}}$ and thus these ions are in the low-spin state $\left(\mathrm{Ru}^{3+}\left(4 \mathrm{~d}^{5}\right): S=1 / 2\right)$. In addition their spin-orbit coupling energy is much larger as compared to the $3 \mathrm{~d}$ ions which consequently implies a much stronger coupling of the spin system to the lattice. Since the orbital momentum $\mathbf{L}$ tends to align along the axis of distortion of the noncubic crystalline field represented in table I by $E^{\text {loc }}$, the direction of the spin $\mathbf{S}$ depends on the relative magnitude of $E_{\text {so }}$ and $E_{\text {exchn }}$. For the $3 \mathrm{~d}$ ions $E_{\text {exch }}>E_{\text {so }}$ and the spin $\mathbf{S}$ is approximately parallel to the exchange field and for the $4 \mathrm{~d} / 5 \mathrm{~d}$ ions $E_{\text {so }}>E_{\text {exch }}$ and $\mathbf{S}$ is approximately parallel to $\mathbf{L}$. Since the magnetic behaviour is essentially governed by the smallest perturbation, the magnitude of the anisotropy is determined by the splitting of the lowest energy levels which is proportional to $E_{\text {so }}$ for $3 \mathrm{~d}$ ions and to $E_{\text {exch }}$ for $4 \mathrm{~d} / 5 \mathrm{~d}$ ions. This difference in magnitude of $E_{\text {so }}$ and $E_{\text {exch }}$ is of significant importance for the calculation of anisotropy and magnetostriction, since $E_{\text {exch }}$ is a strong function of temperature in contrast to $E_{\mathrm{so}}$. While for $4 \mathrm{~d}$ and $5 \mathrm{~d}$ ions the condition $E_{\text {so }}>E_{\text {exch }}$ remains valid for all temperatures, the condition $E_{\text {exch }}>E_{\text {so }}$ for 3 d ions holds only for lower temperatures which implies a different temperature dependence. However, for all configurations the central role of magnetically anisotropic effects has to be attributed to the low-symmetry crystalline fields which fixes the orbital momentum to a certain crystallogra- 


\section{TABLE I}

\section{Relative magnitude of the interactions determining the magnetic behaviour} of the transition-metal ions and the rare earth ions.

Transition-metal ions $3 \mathrm{~d}\left(\mathrm{Fe}^{\text {II }}, \mathrm{Co}^{\text {II }}\right)$

$4 d / 5 d\left(R^{I I I}, \mathrm{Ir}^{\mathrm{IV}}\right)$

Rare earth ions $\left(\mathrm{Tb}^{\mathrm{III}}, \mathrm{Nd} \mathrm{d}^{\mathrm{III}}\right)$

Magnitude of energy level splitting $\left(\mathrm{cm}^{-1}\right)$

$$
\begin{aligned}
E_{\mathrm{e} 1}^{\mathrm{d}}>E_{\mathrm{c}}^{\mathrm{cub}} \gg E_{\mathrm{c}}^{\mathrm{loc}}>E_{\mathrm{exch}}>\cdots \gg E_{\mathrm{so}} \gg E_{\mathrm{c}, \vec{\varepsilon}} \\
E_{\mathrm{c}}^{\mathrm{cub}}>E_{\mathrm{el}}^{\mathrm{d}} \gg E_{\mathrm{so}} \simeq E_{\mathrm{c}}^{\mathrm{loc}}>\cdots \gg E_{\text {exch }} \gg E_{\mathrm{c}, \overrightarrow{\mathrm{z}}} \\
E_{\mathrm{el}}^{\mathrm{f}}>E_{\mathrm{so}} \gg E_{\mathrm{c}}^{\mathrm{cub}}>E_{\mathrm{c}}^{\mathrm{loc}}>\cdots \gg E_{\text {exch }} \gg E_{\mathrm{c}, \overleftrightarrow{\varepsilon}} \\
2-4 \times 10^{4} \leqslant 3 \times 10^{3} \leqslant 3 \times 10^{2}<10
\end{aligned}
$$

phic direction and, thus, the spin via the spin-orbit coupling. The smallest interaction is the strain dependent crystalline field energy $E_{\mathrm{c}, \leftrightarrow}$. The order of magnitude of the energies is given in table I expressed in $\mathrm{cm}^{-1}$. The spin-orbit coupling becomes only effective for those ions which exhibit an orbitally degenerate cubic ground state where the three-fold degenerate $T$-states are most effective. From the $4 \mathrm{~d}$ and $5 \mathrm{~d}$ transition-metal ions only very few ions show such a degenerate ground level like the ions $\mathrm{Rh}^{4+}\left(4 \mathrm{~d}^{5}\right)$, $\mathrm{Ru}^{3+}\left(4 \mathrm{~d}^{5}\right), \quad \mathrm{Ru}^{4+}\left(4 \mathrm{~d}^{4}\right), \quad \mathrm{Pd}^{4+}\left(4 \mathrm{~d}^{6}\right), \quad \operatorname{Re}^{3+}\left(5 \mathrm{~d}^{4}\right)$, $O s^{3+}\left(5 d^{5}\right), O s^{4+}\left(5 d^{4}\right), \mathrm{Ir}^{3+}\left(5 d^{6}\right)$ and $\operatorname{Ir}^{4+}\left(5 d^{5}\right)$ where the considered valence states have been restricted to those which have been mainly observed in other oxides. The most simple configuration is the lowspin $\mathrm{d}^{5}$ configuration which should be considered in some more detail.

The cubic ground state of a low-spin $\mathrm{d}^{5}$ configuration corresponds to that of a $\mathrm{d}^{1}$ configuration except for the sign of the spin-orbit coupling constant. This state is sixfold degenerate and the degeneracy is removed by the local noncubic crystalline field, the spinorbit coupling, the exchange interaction and the increment of crystal field depending on strain. The corresponding Hamiltonian with the energy terms arranged in this sequence is of the form

$\mathscr{H}=V_{\mathrm{c}}^{\mathrm{loc}}(\mathbf{r})+\lambda \mathbf{L} . \mathbf{S}+g \mu_{\mathrm{B}} \mathbf{H}_{\mathrm{exch}} \cdot \mathbf{S}+\delta V_{\mathrm{c}}(\mathbf{r}, \overleftrightarrow{\mathbf{\varepsilon}})$

The exchange interaction is presented in the molecular field approximation and $\lambda$ represents the spin-orbit. coupling constant. Applying this Hamiltonian to a suitable set of wave functions of the cubic ground state its splitting can be calculated. The lowest energy levels can be described by the relation:

$E_{i \perp / i 2}(\alpha, \overleftrightarrow{\varepsilon})=E_{0} \pm A\left[\sqrt{B+C \cos ^{2} \gamma_{i}(\alpha)}+\delta_{i}(\overleftrightarrow{\varepsilon})\right]$

$A$ is proportional to the exchange field and $E_{0}, B$, and $C$ are only functions of $\lambda$ and the matrix element $v$ of the local crystalline field. $\left.\delta_{i} \stackrel{\leftrightarrow}{\varepsilon}\right)$ describes the strain dependence and $\gamma_{i}(\boldsymbol{\alpha})$ denotes the angle between the local axis of distortion and the direction of the magnetization.

2.2 Anisotropy. - To derive the temperature dependence of the anisotropy contributions $\Delta K_{i}$ they have to be correlated to the free energy at certain crystallographic directions since a direct expansion of eq. (6) in powers of the direction cosines gives rise to divergencies at low temperatures. Neglecting higher order anisotropy constants $\Delta K_{1}$ and $\Delta K_{2}$ can be correlated to the free energy according to the relations

$$
\begin{aligned}
& \Delta K_{1}=4(\Delta F[110]-\Delta F[001]) \\
& \Delta K_{2}=9(3 \Delta F[111]+\Delta F[001]-4 \Delta F[110]) .
\end{aligned}
$$

For the anisotropy case we can neglect the strain dependence and for low-spin $\mathrm{d}^{5}$ ions the energy separation of the two lowest levels are relatively small as compared with the separation to the next higher levels. Thus, the effect of the higher levels can be neglected in good approximation. Introducing the splitting $\Delta E_{001}$ of the two lowest levels for $\mathbf{M} \|[001]$ and the quantity

$$
\eta=-\frac{C}{3}\left(\frac{A}{2 \Delta E_{001}}\right)^{2}
$$

the free energy contribution of eq. (6) can be rewritten as

$f^{(i)}(\alpha)=-k T \ln \cosh \left(\frac{\Delta E_{001} \sqrt{1-\eta g_{i}\left(\alpha_{k}\right)}}{2 k T}\right)$

For octahedral sites the functions $g_{i}\left(x_{k}\right)$ are given by :

$$
\begin{aligned}
& g_{1 / 2}=\alpha_{1} \alpha_{2} \pm\left(\alpha_{2} \alpha_{3}+\alpha_{1} \alpha_{3}\right) \\
& g_{3 / 4}=-\alpha_{1} \alpha_{2} \mp\left(\alpha_{2} \alpha_{3}-\alpha_{1} \alpha_{3}\right) .
\end{aligned}
$$

Similar relations hold for the tetrahedral case [9]. Combinings eqs. (5), (9), (10), and (11) the temperature dependence of low-spin $\mathrm{d}^{5}$ ions on octahedral sites with the axis of distortion along a [111] direction can be expressed by the relations

$$
\begin{aligned}
& \Delta K_{1}=2 k T N \ln \left[\frac{\cosh ^{2}(t)}{\cosh (t \sqrt{1+\eta}) \cosh (t \sqrt{1-\eta})}\right] \\
& \Delta K_{2}=\frac{9}{4} k T N \times \\
& \times \ln \left[\frac{\cosh ^{8}(t \sqrt{1+\eta}) \cosh ^{8}(t \sqrt{1-\eta})}{\cosh ^{4}(t) \cosh ^{3}(t \sqrt{1-2 \eta}) \cosh ^{9}(t \sqrt{1+2 / 3 \eta})}\right]
\end{aligned}
$$

where $t=\Delta E_{001} / 2 k T$. These expressions generally hold for all ions where the two lowest levels can be described by eq. (8) and the higher levels do not 
contribute significantly and this applies approximately also to the $3 \mathrm{~d}$ ions $\mathrm{Fe}^{2+}$ and $\mathrm{Co}^{2+}$. However, the functional dependence of the constants $\mathrm{A}, \mathrm{B}$ and $\mathrm{C}$ on the atomic parameters then is different.

Similar relation can be derived for tetrahedral sites [9]. The general features of the $\Delta K_{i}$ can be discussed most easily for low temperatures where these relations reduces considerably. Generally $\Delta K_{1}$ turns out to be positive for octahedral sites and negative for tetrahedral sites while $\Delta K_{2}$ is negative for both sites. For $T=\mathrm{OK}$ the ratio $\Delta K_{2} / \Delta K_{1}$ only depend on the parameter $B / C$. Thereby, in the first case a distortion along the [111] directions and in the second along the [100] directions is assumed. If other axis of distortion are present sign and magnitude of the $\Delta K_{i}$ will change. It should be pointed out that for low-spin $\mathrm{d}^{5}$ ions $\Delta E_{001}$ is proportional to $E_{\text {exch }}$ which itself depends on temperature.

2.3 Magnetostriction, - In correspondence to the anisotropy the magnetoelastic constants can be related to the free energy. If higher order terms are neglected in eq. (2) the magnetoelastic constants are simply related to the functions

$$
f_{p q}(\boldsymbol{\alpha})=\frac{\partial \Delta F(\boldsymbol{\alpha}, \overleftrightarrow{\varepsilon})}{\partial \varepsilon_{p q}}
$$

by the relations

$$
\begin{aligned}
& \Delta b_{1}=f_{33}[010]-f_{33}[001] \\
& \Delta b_{2}=f_{12}[110] .
\end{aligned}
$$

The magnetostriction constants are obtained using eq. (3). With the assumptions made for the anisotropy the functions $f_{p q}(\alpha)$ are obtained from eqs. (5), (8), (10), and (13) yielding

$$
f_{p q}(\boldsymbol{\alpha})=-\frac{N}{2 n} \sum_{i=1}^{n} \frac{\partial \Delta E_{i}}{\partial \varepsilon_{p q}} \tanh \left(\frac{\Delta E_{i}}{2 k t}\right)
$$

where $\Delta E_{i}=E_{2 i}-E_{1 i}$. From eqs. (4), (14), and (15) we can calculate the temperature dependence of the magnetostriction constants. For octahedral sites the result can be expressed by

$$
\begin{aligned}
\Delta \lambda_{100}(T)= & \Delta \lambda_{100}(0) q(T) \tanh (t) \\
\Delta \lambda_{111}(T)= & \frac{\Delta \lambda_{111}(0) q(T)}{1+C} \times \\
& \quad \times\{\tanh (t \sqrt{1+\eta})+C \cdot \tanh (t \sqrt{1-\eta})\}
\end{aligned}
$$

where all constants have been absorbed by $\Delta \lambda_{100}(0)$ and $\Delta \lambda_{111}(0)$. In particular, these are proportional to the concentration and the matrix element over the strain dependent increment of the crystal field where the magnitude of the latter in general is unknown and, thus $\Delta \hat{1}_{100}(0)$ and $\Delta \hat{\gamma}_{111}(0)$ have to be regarded as adjustable parameters. $C$ is essentially only a function of $\eta$ and $q(T)$ represents the relative temperature dependence of the exchange field since $\Delta E_{i}$ is proportional to $H_{\text {exch }}$ according to eq. (8). For octahedral sites $q(T)$ can be well approximated by the specific temperature dependence of the tetrahedral sublattice magnetization. It should be pointed out, that $\Delta E_{001}$ also is proportional to $H_{\mathrm{cxch}}$ and thus to $q(T)$. A slightly different theoretical approach is presented in ref. [11].

3. Comparison of theory and experiment. 3.1. Anisotropy. - The theoretical results of the preceeding chapter can be compared with experimental data of ruthenium- and iridium-substituted garnets and spinels. The most definite cases appear to be the ruthenium-substituted garnets like $\mathrm{Y}_{3} \mathrm{Fe}_{5-x} \mathrm{Ru}_{x} \mathrm{O}_{12}[8$, 21, 22], $\mathrm{Gd}_{3}-\mathrm{Fe}_{5-x} \mathrm{Ru}_{x} \mathrm{O}_{12}$ [23]. In these materials the trivalent ruthenium $\mathrm{Ru}^{3+}\left(4 d^{5}\right)$ on octahedral sites dominate. For very small concentrations the accurate determination of the number of substituted ions $N$ is very difficult. This problem can be avoided by considering the ratio $\Delta K_{2} / \Delta K_{1}$ which is independent on $N$ as obvious from eqs. (12). In figures $3 a, b$ $\Delta K_{2} / \Delta K_{1}$ is plotted versus temperature for the ruthenium-substituted garnets for different concentrations. The independence on concentration is well fulfilled for all temperatures. The solid line represents the theory

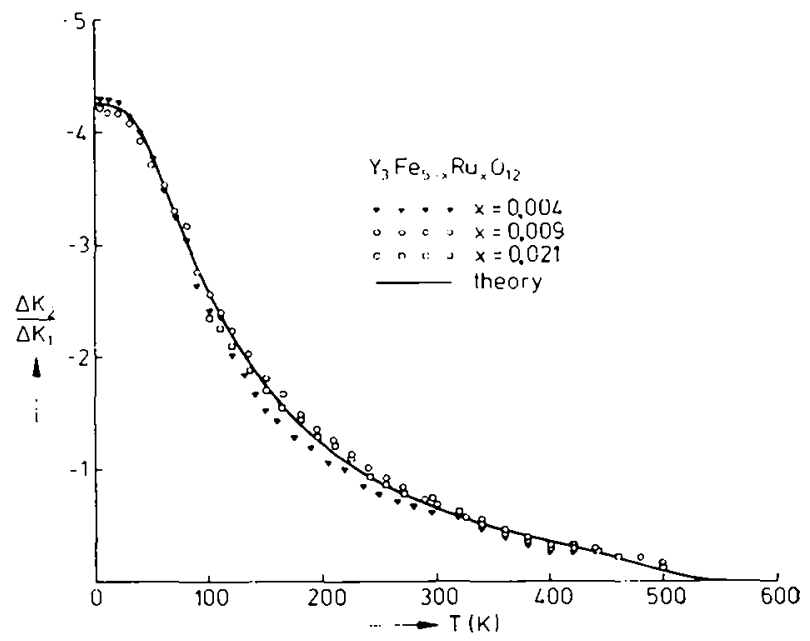

(a)

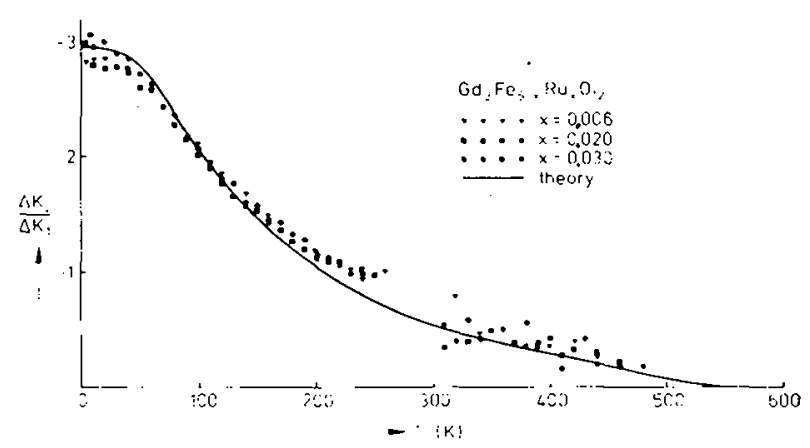

(b)

Fic. 3. - Temperature dependence of the ratio of the anisotropy contributions $\Delta K_{2} / \Delta K_{1}$ of $\mathrm{Ru}^{3+r}\left(4 \mathrm{~d}^{5}\right)$ on octahedral sites in a) yttrium iron garnet $[8,22,23]$ and $b$ ) gadolinium iron garnet [23]. The solid line represents the single-ion theory according to eqs. (12). 
assuming the temperature dependence of the exchange field to be represented by that of the specific tetrahedral sublattice magnetization $\left(\Delta E_{001} \sim q(t)=\sigma_{\mathrm{d}}(t)\right)$. For $\mathrm{d}^{5}$ ions the two atomic parameters $\mu_{\mathrm{B}} H_{\mathrm{exch}} v / \xi$ $(\lambda=-\xi$, where $\xi$ is the one-electron spin-orbit coupling parameter) determine the temperature behaviour of the anisotropic properties. For $\mathrm{Y}_{3} \mathrm{Fe}_{5-x} \mathrm{Ru}_{x} \mathrm{O}_{12}$ (Fig. 3a) the theoretical curve according to eqs. (12) is based on the values $v / \xi=-1.0$ and $g \mu_{\mathrm{z}} H_{\text {exch }}=514 \mathrm{~cm}^{-1}$. The ratio of the local trigonal field and spin-orbit coupling $v / \zeta$ in addition has been measured for the approximately isomorphic system $\mathrm{Y}_{3} \mathrm{Ga}_{5-x} \mathrm{Ru}_{x} \mathrm{O}_{12}$ by paramagnetic resonance yielding $v / \xi=-1.06[24]$. Since these values of $v / \xi$ deduced from independent measurements agree well the exchange interaction between the ruthenium ions and the iron ions has to be regarded as the only adjustable parameter. With a suitable choice of this quantity obviously an excellent fit of the experimental data for $T \leqslant T_{0}$ can be achieved. In the corresponding system $\mathrm{Gd}_{3} \mathrm{Fe}_{5-x} \mathrm{Ru}_{x} \mathrm{O}_{12}$ the temperature dependence of $\Delta K_{2} / \Delta K_{1}$ also can be well described by the single-ion theory as shown in figure $3 b$. The scatter of the experimental data in the room temperature range originates from the presence of the compensation temperature at $T_{\text {comp }}=286 \mathrm{~K}$. For this case the values $v / \xi=-0.48$ and $g \mu_{\mathrm{b}} H_{\mathrm{ex} \text { ch }}=626 \mathrm{~cm}^{-1}$ have been used.

Thus, for different hosts the single-ion theory accounts well for the anisotropy of these low-spin $\mathrm{d}^{5}$ ions. For selected temperature and contributions per ion are summarized in table II. In addition the data of the weakly anisotropic ion $\mathrm{Fe}^{3+}, \mathrm{Cr}^{3+}$ and
$\mathrm{Cu}^{2+}$ and for the most anisotropic $3 \mathrm{~d}$ ion $\mathrm{Co}^{2+}\left(3 \mathrm{~d}^{7}\right.$ in yttrium iron garnet are listed for comparison [5]. It should be noted that the per ion values are not of high accuracy, since in spite of a very careful analysis the determination of $N$ for these small substitutions is quite difficult.

3.2. Magnetostriction. - The magnetostriction of ruthenium-substituted yttrium iron garnet has been investigated by several authors $[10,11,25,16]$. The relative temperature dependence of $\lambda_{100}(T) / \lambda_{100}(0)$ is displayed in figure $4 a$ for different concentrations [25]. The solid line represents the theory according to eqs. (16). In correspondence to the anisotropic behaviour the complete temperature dependence can be well described. For the second magnetostriction constant a similar result is obtained using the atomic parameters already deduced from the fit of the anisotropy data. The effects of ruthenium ions in epitaxially grown garnet films correspond to those in fluxgrown crystals $[27,28]$.

The remaining difficulty in magnetostriction is the calculation of the constants $\lambda_{h k l}(0)$ which are proportional to the matrix elements of the increment of crystalline field depending on stress. Sign and magnitude of these quantities have not yet been studied in a satisfactory manner. Further the strain dependence of the exchange field has not been considered. For example the $\lambda_{h k l}(0)$ of the $\mathrm{Co}^{2+}$ ions are much smaller and in addition $\lambda_{10 u}(0)$ is negative as can be seen from table II. The anisotropy constants, however, correspond to those of the $\mathrm{Ru}^{3+}$ ions. This different behaviour in the anisotropy and magnetostriction

\section{TABLE II}

Anisotropy and magnetostriction contributions of the $3 \mathrm{~d}$ ions $\mathrm{Fe}^{3+}, \mathrm{Cr}^{3+}, \mathrm{Cu}^{2+}, \mathrm{Co}^{2+}$ and the $4 \mathrm{~d}$ ion $\mathrm{Ru}^{3+}$ in garnets of composition $\mathrm{Y}_{3} \mathrm{Fe}_{5-x} \mathrm{M}_{x} \mathrm{O}_{12}$ and $\mathrm{Gd}_{3} \mathrm{Fe}_{5-x} \mathrm{M}_{x} \mathrm{O}_{12}$

\begin{tabular}{|c|c|c|c|c|c|c|c|c|c|}
\hline $\begin{array}{l}\text { Composition } \\
\text { of the host }\end{array}$ & $\begin{array}{r}\text { Substituted ion } \\
\text { (configuration) }\end{array}$ & $\begin{array}{l}\text { Cubic } \\
\text { ground } \\
\text { state }\end{array}$ & $\begin{array}{c}T \\
(\mathrm{~K})\end{array}$ & $\begin{array}{l}\Delta K_{1} / N \\
\left(\mathrm{~cm}^{-1}\right)\end{array} \mid$ & $\begin{array}{l}\Delta K_{2} / N \\
\left(\mathrm{~cm}^{-1}\right)\end{array}$ & Ref. & $10^{4} \lambda_{100 / x}$ & $10^{4} \lambda_{111 / x}$ & Ref. \\
\hline $\mathrm{Y}_{3} \mathrm{Fe}_{5} \mathrm{O}_{12}$ & \multirow{2}{*}{$R u^{3+}\left(4 d^{5}\right)$} & \multirow{2}{*}{${ }^{2} \mathrm{~T}_{2 g}$} & \multirow{2}{*}{$\begin{array}{c}4.2 \\
77 \\
295 \\
4.2 \\
130 \\
330 \\
\end{array}$} & \multirow{2}{*}{$\begin{array}{c}28 \\
22 \\
2 \\
25 \\
8 \\
0.4\end{array}$} & \multirow{2}{*}{$\begin{array}{rc}- & 120 \\
-\quad 68 \\
-\quad 3 \\
-\quad 70 \\
-\quad 14 \\
-\quad 0.2 \\
\end{array}$} & \multirow[t]{2}{*}[8,9,23]{} & \multirow[t]{2}{*}{$\begin{array}{l}2.7 \\
2.7 \\
2.5\end{array}$} & \multirow[t]{2}{*}{$\begin{array}{l}2.9 \\
2.6 \\
0.8\end{array}$} & \multirow[t]{2}{*}{ [10] } \\
\hline $\mathrm{Gd}_{3} \mathrm{Fe}_{5} \mathrm{O}_{12}$ & & & & & & & & & \\
\hline \multirow{4}{*}{$\mathrm{Y}_{3} \mathrm{Fe}_{5} \mathrm{O}_{12}$} & $\mathrm{Fe}^{3+}\left(3 \mathrm{~d}^{5}\right)$ & ${ }^{6} \mathrm{~A}_{1 \mathrm{~g}}$ & 4.2 & -0.005 & 0 & [14] & -0.025 & 0.02 & [14] \\
\hline & $\mathrm{Cr}^{3+}\left(3 \mathrm{~d}^{3}\right)$ & ${ }^{4} \mathrm{~A}_{28}$ & 4.2 & -0.05 & - & [15] & - & - & - \\
\hline & $\mathrm{Cu}^{2+}\left(3 \mathrm{~d}^{9}\right)$ & ${ }^{2} \mathrm{~T}_{2 \mathrm{~g}}$ & $\begin{array}{c}4.2 \\
77^{2} \\
295\end{array}$ & $\begin{array}{l}-0.2 \\
-0.18 \\
-0.05\end{array}$ & $\begin{array}{c}\sim-0.01 \\
0 \\
0\end{array}$ & [16] & - & -- & - \\
\hline & $\mathrm{Co}^{2+}\left(3 \mathrm{~d}^{7}\right)$ & ${ }^{2} \mathrm{~T}_{1 \mathrm{~g}}$ & $\begin{array}{c}4.2 \\
77 \\
292\end{array}$ & $\begin{array}{r}27 \\
21 \\
1\end{array}$ & $\begin{array}{lc} & 124 \\
- & 71 \\
- & 0.5\end{array}$ & [5] & $\begin{array}{l}-0.5 \\
-0.6 \\
-0.4\end{array}$ & $\begin{array}{l}1.0 \\
1.2 \\
0.7\end{array}$ & [5] \\
\hline
\end{tabular}




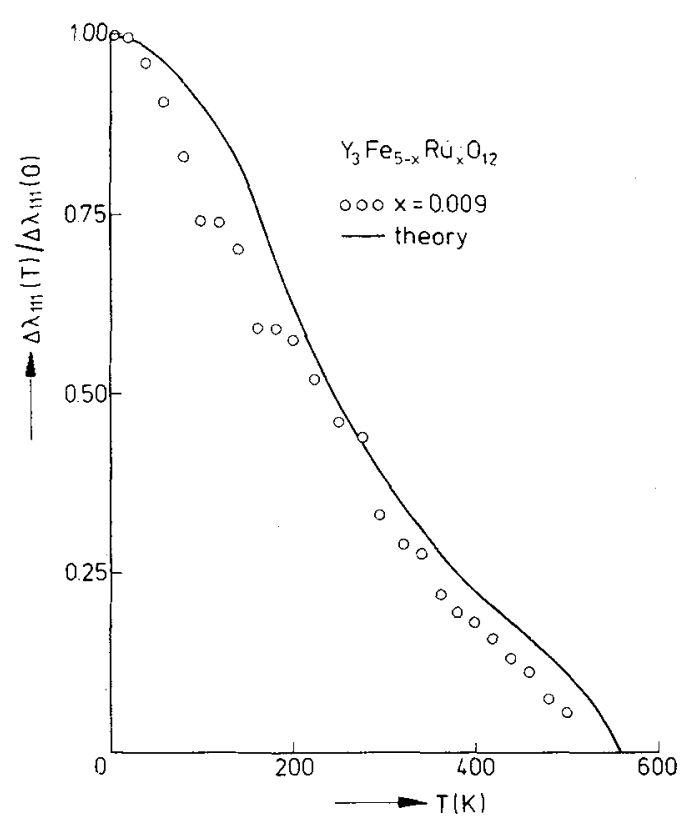

(a)

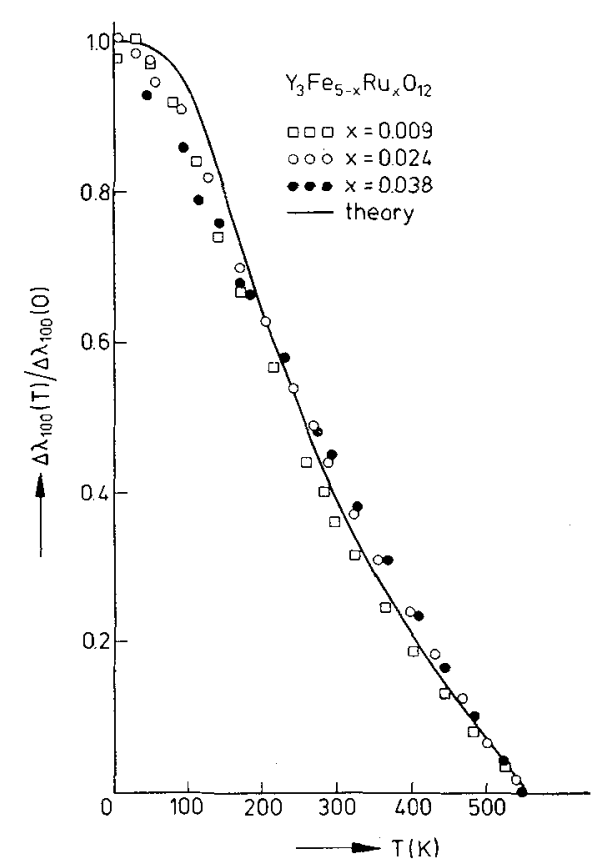

(b)

FIG. 4. - The temperature dependence of the reduced magnetostriction contributions a) $\Delta \lambda_{100}(T) / \Delta \lambda_{100}(0) \quad[25]$ and $b$ ) $\Delta \lambda_{111}(T) / \Delta \lambda_{111}(0)$ for $\mathrm{Ru}^{3+}\left(4 \mathrm{~d}^{5}\right)$ on octahedral sites in yttrium iron garnet. The solid line represents the single-ion theory according to eqs. (16).

contributions can also be observed for other anisotropic ions and the explanation requires further detailed investigations.

4. Complex behaviour of $4 \mathrm{~d}$ and $5 \mathrm{~d}$ ions. - The $4 \mathrm{~d}$ and $5 \mathrm{~d}$ transition-metal ions are known to be present in different valencies in many compounds. Further their ionic radius in the low-spin state is of the same size or even smaller than that of the trivalent iron ions which implies that no site preference can be predicted from the size of these ions. Thus, in general a very complex situation can occur where a certain ion in more than one valence state is present and in addition these ions occupy both tetrahedral and octahedral sites. The condition for these various states concerning valency and site occupation is essentially determined by the growth conditions of the fluxgrown crystals and the impurities present.

In table III the results for the garnet and spinel hosts are summarized where a strong evidence is present for such a complex behaviour. A very striking case is that of the yttrium iron-aluminium garnets where for small aluminium content the anisotropy contributions of the ruthenium ions is in accordance with that of yttrium iron garnet, but for higher aluminium content $\Delta K_{1}$ changes sign indicating a stronger preference for tetrahedral sites [29]. The presence of different valencies is also indicated by the optical studies of garnets [30], the magnetic properties of yttrium iron garnets containing zinc and of calcium-bismuth iron-vanadium garnets [31-33]. For iridium-substituted yttrium iron garnet the tretravalent state also is a low-spin $\mathrm{d}^{5}$ configuration and for this ion comparable effects are expected with respect to $\mathrm{Ru}^{3+}$. However, $\Delta K_{1}$ turns out to be very small and $\Delta K_{2}$ positive indicating a compensation of the contributions from different sites. Therefore, the interpretation of the anisotropy and magnetostriction assuming a pure octahedral occupation leads to a positive value of $v / \xi[12,13]$ in contrast to paramagnetic resonance measurements [34-36]. Indeed optical studies indicate the presence of $\mathrm{Ir}^{4+}$ on tetrahedral sites [36, 37].

In the spinel host the $\mathrm{Ir}^{4+}$ on octahedral sites seems to dominate [38], however, the ratio $\Delta K_{2} / \Delta K_{1}$ shows a concentration dependence which indicates the presence of an other valency or different site occupation in the crystals with different concentration. A similar uncertainty about the valence state and the site occupation is present in the ruthenium-substituted nickel and lithium ferrites $[39,40]$.

An accurate description of the behaviour of the ruthenium and iridium ions in these hosts requires further work. In particular independent measurements as optical studies, paramagnetic resonance on the corresponding diamagnetic hosts and nuclear spin echo measurements are necessary to obtain additional information on the atomic parameters of the electronic configurations and about the site occupation. Otherwise the number of unknown parameters is too large and a comparison of experimental magnetic data with the single-ion theory will not give reliable results. Other ions like palladium, rhodium, rhenium, osmium and platinum would be of large interest, however, no results have been reported. The incorporation of these ions in a particular valence state in garnets and spinels in some cases is very difficult owing to the chemical conditions of the growth process. 


\section{TABLE III}

Anisotropy and magnetostriction contributions of the ruthenium and iridium ions in garnets and spinel ferrites. In these hosts the ions are present presumably in different valencies and occupy both tetrahedral and octahedral sites

\begin{tabular}{|c|c|c|c|c|c|c|c|}
\hline Host & $\begin{array}{l}\text { Substituted ion } \\
\text { (configuration) }\end{array}$ & $\begin{array}{c}T \\
(\mathrm{~K})\end{array}$ & $\begin{array}{l}\Delta K_{1} / N \\
\left(\mathrm{~cm}^{-1}\right)\end{array}$ & $\begin{array}{l}\Delta K_{2} / N \\
\left(\mathrm{~cm}^{-1}\right)\end{array}$ & $10^{4} \Delta \lambda_{100 / x}$ & $10^{4} \Delta \lambda_{111 / x}$ & Ref. \\
\hline $\mathrm{Y}_{3} \mathrm{Fe}_{4.7} \mathrm{Al}_{0.3} \mathrm{O}_{12}$ & \multirow{4}{*}{$\mathrm{Ru}^{3+}\left(4 \mathrm{~d}^{5}\right), \mathrm{Ru}^{4+}\left(4 \mathrm{~d}^{4}\right)$} & $\begin{array}{c}4.2 \\
77 \\
295\end{array}$ & $\begin{array}{l}8.7 \\
6.8 \\
0.4\end{array}$ & $\begin{array}{l}-45.6 \\
-24.5 \\
-\quad 0.3\end{array}$ & - & - & [29] \\
\hline $\mathrm{Y}_{3} \mathrm{Fe}_{4.1} \mathrm{~A}_{0.9} \mathrm{O}_{12}$ & & $\begin{array}{c}4.2 \\
77 \\
295\end{array}$ & $\begin{array}{l}-5.1 \\
-2.2 \\
-0.1\end{array}$ & $\begin{array}{l}-17.0 \\
-10.1 \\
\sim 0\end{array}$ & - & - & [29] \\
\hline $\mathrm{Y}_{3} \mathrm{Fe}_{5-y} \mathrm{Zn}_{y} \mathrm{O}_{12}$ & & $\begin{array}{r}77 \\
295\end{array}$ & $\begin{array}{c}30 \\
2\end{array}$ & 一 & - & - & {$[31,32]$} \\
\hline $\mathrm{Ca}_{2.7} \mathrm{Bi}_{0.3} \mathrm{Fe}_{3.65} \mathrm{~V}_{1.35} \mathrm{O}_{12}$ & & $\begin{array}{r}77 \\
295\end{array}$ & $\begin{array}{l}-2.8 \\
-0.8\end{array}$ & - & - & - & [33] \\
\hline $\mathrm{Y}_{3} \mathrm{Fe}_{5} \mathrm{O}_{12}$ & $\operatorname{Ir}^{3+}\left(5 d^{6}\right), \operatorname{Ir}^{4+}\left(5 d^{5}\right)$ & $\begin{array}{c}4.2 \\
77 \\
295 \\
\end{array}$ & $\begin{array}{l}1.6 \\
1.5 \\
0.2 \\
\end{array}$ & $\begin{array}{l}26 \\
18 \\
0.1\end{array}$ & $\begin{array}{l}-5.1 \\
-4.8 \\
-1.9\end{array}$ & $\begin{array}{l}\sim-0.2 \\
\sim-0.1 \\
\sim \quad 0\end{array}$ & {$[12,13]$} \\
\hline $\mathrm{NiFe}_{2} \mathrm{O}_{4}$ & $\mathrm{Ir}^{4+}$ & $\begin{array}{c}4.2 \\
77 \\
298\end{array}$ & $\begin{array}{r}2.5 \\
1.4 \\
\sim 0.1\end{array}$ & $\begin{array}{c}-\overline{10} \\
-7 \\
\sim-0.5\end{array}$ & - & 一 & [38] \\
\hline $\mathrm{NiFe}_{2} \mathrm{O}_{4}$ & \multirow{2}{*}{$\mathrm{Ru}^{3+}\left(4 d^{5}\right), \mathrm{Ru}^{4+}\left(4 \mathrm{~d}^{4}\right)$} & $\begin{array}{r}77 \\
150 \\
295 \\
\end{array}$ & $\begin{array}{l}-13 \\
-9.8 \\
-3.6 \\
\end{array}$ & $\begin{array}{l}-18 \\
=\quad 7.9 \\
-\quad 1.4 \\
\end{array}$ & $\sim 0$ & $\sim 0$ & [39] \\
\hline $\mathrm{Li}_{0.5} \mathrm{Fe}_{2: 5} \mathrm{O}_{4}$ & & $\begin{array}{r}77 \\
150 \\
295\end{array}$ & $\begin{array}{l}+1.5 \\
+0.8 \\
+0.4\end{array}$ & $\begin{array}{l}-16 \\
=\quad 4.8 \\
-\quad 0.4\end{array}$ & $\begin{array}{l}-3.5 \\
-2.0 \\
\sim 0\end{array}$ & $\begin{array}{l}-5.8 \\
-3.9 \\
-2.9\end{array}$ & [39] \\
\hline
\end{tabular}

5. Conclusion. - The $4 \mathrm{~d}$ and $5 \mathrm{~d}$ ions exhibit large anisotropy and magnetostriction contributions in garnets and spinel ferrites. In particular the low-spin $\mathrm{d}^{5}$ ion $\mathrm{Ru}^{3+}$ on octahedral sites in garnets has been investigated in some more detail since in this case the experimental data are in excellent agreement with the predictions of the single-ion theory. For this configuration a very simple level structure is present owing to the fact that the spin-orbit coupling is much larger than the exchange field. This condition leads to expli- cit relations for the temperature dependence of anisotropy and magnetostriction in contrast to any other strongly anisotropic ion. The good description of the experimental results by the single-ion theory attributes this configuration a special status in understanding of magnetically anisotropic effects in magnetic oxides.

For other hosts and ions more complicated configurations with respect to valence states and site occupation occur and further work is needed to obtain an accurate description of the observed effects.

\section{References}

[1] HANSEN, P., Philips Tech. Rev. 35 (1975) 225.

[2] Dionne, G. F. and Goodenough, J. B., Mater. Res. Bull. 7 (1972) 749.

[3] Hansen, P., Tolksdorf, W. and Schuldt, J., J. Appl. Phys. 43 (1972) 4740.

[4] Hansen, P., J. Appl. Phys. 48 (1977) to be published.

[5] Hansen P., KRISHNan R. and TolksDorf, W., unpublished.

[6] Krishnan, R., Phys. Stat. Sol. (a) 1 (1970) K 17.

[7] Hansen, P., Philips Res. Repts. Suppl. No. 71970.

[8] Hansen, P., Phys. Rev. B 3 (1971) 862.

[9] Hansen, P., Phys. Stat. Sol. (b), 47 (1971) 565.

[10] Krishnan, R., CaGan, V., Rivoirf, M., AIP Conf. Proc. 5 (1971) 704.

[11] HANSEN, P., Phys. Rev. B 8 (1973) 246.
[12] Hansen, P., Schuldt, J., Tolksdorf, W., Phys. Rev. B 8 (1973) 4274.

[13] Hansen, P., Proc. Intern. Conference Magnetism (Moscow), 1974, Vol. III, 386.

[14] Ha.ssen, P., J. Appl. Phys. 45 (1974) 3638.

[15] Krishnan, R., AIP Confer. Proc. 10 (1972) 112.

[16] Krishnan, R., J. Appl. Phys. 40 (1969) 1557.

[17] Wolf, W. P., Phys. Rev. 108 (1958) 1152.

[18] Yosida, K., Tachiki, M., Progr. Theor. Phys. 17 (1957) 331.

[19] Slonczweskr, J. C., Phys. Rev. 110 (1958) 1341.

[20] Таснiкi, M., Progr. Theor. Phys. 23 (1960) 1055.

[21] Ballahusen, C. J., Introduction to Ligand Field Theory, (McGraw-Hill Book Company, Inc., New York) 1962. 
[22] Hansen, P., Tolksdorf, W., J. Physique Colloq. 32 (1971) C 1-200.

[23] Hansen, P., Phys. Rev. B 5 (1972) 3737.

[24] Miller, I. A., Offenibacher, E. L., Phys. Rev. 166 (1968) 269.

[25] Delacheisserie, E. T., J. Physique 37 (1976) 379.

[26] Hodges, J. A., Chantereau, F., J. Physique 34 (1973) 623.

[27] Krumme, J.-P., Hansen, P., Bartels, G. and Mateika, D., J. Appl. Phys. 46 (1975) 2801.

[28] Krishnan, R., Phys. Stat. Sol. (a) 30 (1975) K 177.

[29] Hansen, P., TOLKSDORF, W., Intern. J. Magnetism 3 (1972) 81.

[30] TOLKSDORF, W., unpublished.

[31] Krishnan, R., Oudet, X., Porte, M. and Marais, A., Intern. Conference on Magnetism, Amsterdam 1976, paper $7 \mathrm{C} 3$.
[32] KrishNan, R., unpublished.

[33] Krishnan, R., Second International Conference on Ferrites, Paris 1976, paper A 2-4, J. Physique Collog. 38 (1977) Cl.

[34] Offendacher, E. L., Waldman, H., Bull. Am. Phys. Soc. 13 (1968) 435.

[35] Hodges, J. A., Phys. Stat. Sol. (b) 67 (1975) 715.

[36] Andlauer, B., Schneider, J. and Tolksdorf, W., Phys. Stat. Sol. (b) 73 (1976) 533.

[37] Andlauer, B., and Tolksdorf, W., Intern. Conference on Magnetism, Amsterdam 1976, paper 9E 4.

[38] Krishnan, R., AIP Conf. Proc. 1976, 29, 678.

[39] Hansen, P., Schuldt, J., Hoekstra, B. and Damen, J. P. M., Phys. Stat. Sol. (a) 30 (1975) 289.

[40] Krishnan, R., Phys. Stat. Sol. (a) 4 (1971) K 177. 